\section{Discussion}

Sporadic cases of cryptococcosis are known to occur throughout Africa (Bhagwandeen, 1969; Mpairwe and Patel, 1970; Gelfand, 1972; Siddorn, 1977). Pulmonary cryptococcosis masquerades as bronchial carcinoma or tuberculosis. The correct clinical diagnosis can sometimes be established by identification of the organisms in the sputum. Repeated examination of sputum on careful search, however, failed to show the organisms in the present case, a finding difficult to explain. Tuberculosis was suspected, and treatment was given without improvement. The operative and macroscopic necropsy findings were not suggestive of fungal disease, and the correct diagnosis was confirmed only by histopathological examination. Since mycosis was not suspected at necropsy, tissue was not collected for culture. Nevertheless, the morphological characteristics shown by routine haematoxylin-eosin and special stains fulfil the requirements outlined by Symmers (1953) and MacGillivary (1966) for identification of Cryptococcus in histology sections.
Cryptococcosis presenting as a mediastinal mass has not previously been reported.

We are grateful to Professor $\mathrm{L}$ Wasornu and $\mathrm{Mr}$ $\mathrm{R}$ Carruthers for invaluable advice and $\mathbf{M r} \mathbf{M} \mathbf{A}$ Ansary for the illustrations.

\section{References}

Bhagwandeen, S B (1969). Disseminated cryptococcosis. Medical Journal of Zambia, 2, 203-204.

Gelfand, M (1972). Cryptococcal meningitis. Central African Journal of Medicine, 18, 248-250.

MacGillivary, J B (1966). Two cases of cryptococcosis. Journal of Clinical Pathology, 19, 424-428.

Mpairwe, Y, and Patel, K M (1970). Cryptococcal meningitis in Mulago Hospital, Kampala. East African Medical Journal, 47, 445-447.

Siddorn, J A (1977). Unpublished data.

Symmers, W St C (1953). Torulosis. Lancet, 2, 10681076.

Requests for reprints to: P Sinha, FRCS, Department of Surgery, University Teaching Hospital, School of Medicine, University of Zambia, PO Box RW 110, Lusaka, Zambia.

\title{
Calendar for Thoracic Society Meetings
}

1979

1-3 February 1979

at Royal College of Physicians, London.

Members of American Thoracic Society are invited to attend this meeting.

6-7 June 1979

in Paris-joint meeting with French Thoracic Society.

1980

7-9 February 1980

at Royal College of Physicians, London (date to be confirmed).

3-4 July 1980

at Durham. Members of BTA and of the Belgian Thoracic Society are particularly invited to attend this meeting; details will be circularised.

For further details contact Dr S W Clarke, Department of Thoracic Medicine, Royal Free Hospital, Pond Street, London NW3 2QG. 